\title{
An overview of Brazilian palliative care
}

\author{
Keywords: heterogeneous, promulgation, cancer, health, care
}

Abbreviations: PC, palliative care; NAPC, national academy of palliative care; FMC, federal medical council

\section{Introduction}

The reports of Braziliam Palliative Care (PC) history of in show that this modality of intervention was initiated in public health in 1983 , in Rio Grande do Sul, followed by São Paulo, Santa Catarina and Paraná. In Rio de Janeiro, in 1998, an exclusive unit of PC was created in a hospital which belonged to the National Cancer Institute. In the private system, the reports are heterogeneous, with non-systematized services, dependent on the individual motivation of professionals who sought training abroad, in the 2000 s and who are present today disseminated by the country, but with still reduce number. ${ }^{1,2}$

The Palliative care progress in Brazil due to the movement of professional categories and advanced in 2005 for two reasons: the promulgation of the national cancer care policy that required the provision $\mathrm{PC}$ as a service integrated with highly complex oncology and the creation of the National Academy of Palliative Care (NAPC). ${ }^{3}$ This non-governmental entity, multiprofessional, acts in the dissemination, education and political actions related to Palliative Care. NACP's actions are currently mainly focused on the recognition of the medical specialty, conceptual and practical dissemination among the professional categories and its feasibility in the health systems, both public and private, seeking to guarantee access to Palliative Care To all Brazilians. In view of the need to insert the concept in a technically correct way and looking at the expansion of PCs in Brazil, in 2006 the Federal Medical Council (FMC) published a resolution in which it cited the PC's doctor actions as irreversibility of the patient's state of illness, through the consent of the same or a legal representative. From this moment on, intense discussions began to emerge and the PCs began to gain prominence until, in 2009, the new Code of Medical Ethics included Palliative Care in different chapters as a medical act and that should be carried out in the face of the appropriate clinical situations. ${ }^{4}$ Subsequently, in 2011, palliative medicine was promoted to an area of action in addition to oncology, such as geriatrics, pediatrics and intensive medicine; FMC, in 2012, recognizes the autonomy of the patient regarding his decisions in the termination phase of the disease, based on the living will as a guiding tool and facilitator of communication between patients, family and physicians. Finally, in 2016, FMC recognizes the need to stimulate the development of palliative care units to target patients who are not eligible for Intensive Care Unit for their clinical condition of disease irreversibility. ${ }^{4}$

However, Brazil lacks essential items for the consolidation of Palliative Care:

i. The predominance of the hospital-centered teaching pattern. This reality is found in all professions in the health field, which contributes to the scarcity of insertion of alternative models of care. This predominance of the hospital-centered pattern of education promotes incomplete care education, since it weakens other models such as primary care, home care, nursing homes and hospice.
Volume I Issue 3 - 2017

\author{
Fonseca $A,{ }^{1,2}$ Fini $D^{1}$ \\ 'Procare Saúde Home care, Brazil \\ ${ }^{2}$ Silvestre Adventist Hospital, Brazil
}

Correspondence: Fonseca A, Procare Saúde Home care, Republica do Peru, 48I/903, Zip code 2202I-040, Rio de Janeiro, Brazil, Email anelise1976@gmail.com

Received: March 25, 2017| Published: August 02, 2017

ii. Recognition of palliative medicine as a medical specialty.

iii. Shortage of public health policy focused on non-oncological diseases that include PCs as a possible model of care, breaking the current paradigm of exclusivity for oncological pathologies.

iv. Creation of an efficient system for dispensing primordial medications, such as opioids, in both public and private pharmacies.

v. A reorganization of the private system aimed at encouraging service providers to offer palliative care and re-adjust the salary policy of palliative professionals, which will contribute to a paradigm shift in the payment, now focused on the "fee for service".

vi. The regulation of alternative models of care, mainly home care. In this regard there is an intense debate, aiming at a perception that the existing barriers need to be overcome in a short time for the sustainability, including financial, of the system itself.

It is important to emphasize that in the face of the aging process and the epidemiological transition, to streighten home care together with palliative care is fundamental. Brazil will soon have $20 \%$ of the elderly and the number of people with chronic diseases, both oncological and non-oncologic, such as dementias, an example of an incurable disease progressively incapacitating and long survival, will increase significantly. As a consequence, we will face the growth of the demand for a care model more appropriate to the chronic condition of the patient, what for this purpose, PCs must and should be a reality. ${ }^{5,6}$ The opportunity to perform end-of-life care centered on the home environment can be an advance in the assistance model. The management of the patient's comfort at home, the frequent presence of the family, especially assisting in the care and follow-up of the preparation of the grieving moment are important processes of the PC and can be performed if they are inserted in the home care. Therefore, the intersection between home care and palliative care is clearly identified and, if it is practiced in an organized way and with technical quality, will represent another important change in the paradigm of the health care model in the health system in Brazil. ${ }^{7}$

Besides, another idea to be highlighted is that due to the unique nature of the care relationship that is built in the $\mathrm{PC}$, with the valuation of the autonomy of the patient and his relatives, in the end of this model contributes to the development of a more efficient assistance of the health system. However, for this purpose, it is essential that Brazil prepares itself technically for this, which implies changes, such as: the 
curricular grades of graduation courses; Incentives for the technical training of professionals, including the participation of societies; The reorganization of care practices, reducing therapeutic obstinacy and developing skills such as communication; The development of a specific policy for palliative care with rupture of the current hospitalcentered or hospital-centered pattern.

Finally, what is expected is that we can change Brazil's current panorama with improved health practices, encouraging patients' autonomy by broadening the scope of care beyond a paternalistic view, so that we can achieve the maturity and the strengthening of our society.

\section{Acknowledgements}

None.

\section{Conflict of interest}

The author declares no conflict of interest.

\section{References}

1. Figueiredo MTA. Palliative care Brasil's history. Revista Ciências em Saúde. 2011;1(2).

2. Hermes HR, Lamarca ICA. Palliative care: an approach based on the professional health categories. Ciência \& Saúde Coletiva. 2013; 18(9):2577-2588.

3. http://paliativo.org.br/

4. http://www.portal.cfm.org.br/

5. http://www.neadsaude.org.br/

6. Fonseca A. The integrated care in health private system in Brasil. Attention's model of health to elderly people. Sergio Arouca, Oswaldo Cruz Institute Fiocruz Rio de Janeiro: Springer; 2015.

7. Fonseca A. Reflexions about home care in Brasil. NEAD. 2016;1:1-31. 